\title{
Prevalence of Premarital Sex and Related Risky Practices Among Students of Ayer Tena Health Science and Business College, Addis Ababa, Ethiopia: A cross-sectional study
}

\section{Dagim Birri ( $\nabla$ dagimj@yahoo.com )}

Addis Ababa University College of Natural Sciences

Mihiretu Kumie

Ayer Tena Health Science and Business College

\section{Research}

Keywords: prevalence, premarital sex, risky practice, college students, Ethiopia

Posted Date: August 24th, 2020

DOI: https://doi.org/10.21203/rs.3.rs-54623/v1

License: (a) (1) This work is licensed under a Creative Commons Attribution 4.0 International License. Read Full License 


\section{Abstract}

Background: Premarital sex may result in sexually transmitted infections (STIs) and unwanted pregnancy. Published reports on the prevalence premarital in private colleges in Ethiopia are limited. This study aimed at assessing the prevalence of premarital and risky behaviours among students of Ayer Tena Health Science and Business College, Addis Ababa, Ethiopia.

Methods: A cross-sectional study was conducted among of Ayer Tena Health Science and Business College, Addis Ababa, Ethiopia. A semi-structured questionnaire was used to collect data from 390 students that were selected by systematic random sampling. Data analysis was done using SPSS version 23. Associations between variables were determined using chi-square test.

Results: The study participants consisted of $81 \%$ females, $73.7 \%$ Christians, $58 \%$ business students, 56.8 $\%$ degree students, $62.1 \%$ regular students and $49.1 \%$ fresh students. We found that $23.3 \%$ of the students had exprienced premarital sex, of which $43.5 \%$ had sex in the last 12 months, $14.3 \%$ were homosexuals, and $20 \%$ started sex before 18 . About $68.2 \%$ never used condom at the first sex and $60 \%$ had history of having sex without condom. About $51.3 \%$ did not plan for the first sex. Nearly $34 \%$ had multiple sexual partners in their life time and $15.5 \%$ had multiple current sexual partners. From 334 respondents, $14.7 \%$ said that oral contraceptive pills prevent sexually STIs. Nearly $59 \%(47 / 80)$ of the study subjects did not have a practice of requesting a new sexual partner for STIs test result. Many students had a history of watching pornography (17.3\%), drinking alcohol (17.3\%) and taking drugs (3\%). Among 65 female students, $20 \%$ had a history of pregnancy, of which $46.2 \%$ have done abortion. Among those who practiced sexual intercourse, 5.9\% had history of STIs, including HIV. Premarital sex was common among males, Christians, health students, non-regular students, degree students, and among those who never attended religious services, live alone, have income, watch pornography, believe that oral contraceptive pills prevent STIs, and take alcohol.

Conclusion: The prevalence of premarital is high among the study participants. Risky behaviors and misconceptions are also common. Hence, it would be better to devise and implement effective intervention strategies to reverse the situation.

\section{Plain English Summary}

Premarital sex may cause in sexually transmitted infections (STIs) and unwanted pregnancy. This study aimed to assess the prevalence of premarital and risky behaviours among students of Ayer Tena Health Science and Business College (ATHSBC), Addis Ababa, Ethiopia.

A questionnaire was used to collect data from 390 randomly selected students of ATHSBC, from April to May 2019. Associations between variables were determined using chi-square test.

The study participants included 316 females, 282 Christians, 228 business students, 221 degree students, 242 regular students and 191 fresh students. Of 290 students, 88 had exprienced premarital sex. About 
58 never used condom at the first sex, and 52 had history of having sex without condom. Nearly 28 and 10 had multiple sexual partners in their life time and currently, respectively. From 332 students, 48 said oral contraceptive pills prevent STIs. Many students had a history of watching pornography $(63 / 365)$, drinking alcohol (63/369) and taking drugs (11/367). Among 65 female students, 13 had a history of pregnancy, of which 6 have done abortion. From 85 students who practiced sexual intercourse, 5 had history of STIs. Premarital sex was common among males, Christians, health students, non-regular students, degree students, and among those who never attended religious services, live alone, have income, watch pornography, believe that oral contraceptive pills prevent STIs, and take alcohol.

In conclusion, the prevalence of premarital was high among the students. Risky behaviors and misconceptions are also common. This calls for implementation of effective intervention strategies to reverse the situation.

\section{Background}

It is well-known that human beings are borne with reproductive system that is responsible for reproduction. The primary reason for being bornewith sexual organs and for having sex is for reproduction which a means of continuation of human generations. Human beings have sex not only for the purpose of reproduction but also to derive satisfaction and happiness, and to make business. Sex between married couples is meant for reproduction and/or satisfaction, whereas sex before marriage (premarital sex) can be meant for satisfaction, business and experience sex.It might also be the result of rape. Whatever the reason is, premarital sex is unacceptable in many countries, including Ethiopia, for cultural and religious reasons [1-3]. However, many adolescents and youths do not care about culture or religion and they practice premarital sex[4]. This is especially true when opposite sexes get the chance to come together. One such opportunity is provided by educational institutions such as schools, colleges and universities, where students from a diverse background meet with each other. For many students, educational institutions are places where they get boy/girlfriends and start to engage in premarital sex.Although sex by itself is a natural human need, it can be dangerous when it is unsafe.Unsafe sex is a risky sexual intercourse that is performed without condom (unprotected sex), with multiple sexual partners (promiscuous sex), with commercial sex workers or at early age (early sex).

Unsafe premarital sex can usually lead to unwanted (unplanned) pregnancy and infections with any of the at least 30 sexually transmitted infections (STIs), and studies have shown that many university students have borne these consequences[5]. Unintended pregnancy can be associated with difficulty in delivery (even death), unplanned parenthood, and economic difficulty in bringing up the child, abortion, embarrassment/shame and discontinuation of study among students. Every year, an estimated 21 million girls aged 15 to 19 years and 2 million girls aged under 15 years become pregnant in developing countries [6, 7]. A national wide survey in china showed that $6.3 \%$ of unmarried youth have become pregnant [8].Abortion may bring about bad feelings due to destroying own fetus, and body injury, infection and/or death if unsafe. Globally, an estimated 3.9 million girls aged 15 to 19 undergo abortion every year [6]. 
STIs can lead to morbidity which may make victims incapable of performing daily activities (making them economic burden to parents and country) and damaged/nonfunctional reproductive organs (e.g., genitals), genital and other cancers, pelvic inflammatory disease, which may result in ectopic pregnancy (can cause maternal death during pregnancy) andinfertility, increased vulnerability to other STIs or other infections, all of which may result in loss of happiness and peace of mind. In the worst case, they can result inloss of own precious life, thwarting of goals and visions, making parents sad and helpless and orphaning children (which may lead to their prostitution and poverty), and divorce. STIs can also pass to the fetus, newborn, or infant through the placenta, during passage through the birth canal, or after birth through breast-feeding or close direct contact. This can lead to spontaneous abortion, stillbirth, premature rupture of membranes, low birth weight, and preterm delivery, and damage to the central nervous system, eyes, and auditory system of the child.

Pregnancy and childbirth complications are the major cause of mortality among 15 to 19 year-old girls worldwide, and $99 \%$ of global maternal deaths of women aged 15 to 49 years occurs in low and middleincome countries[9]. Half of pregnancies among girls aged 15 to 19 years in developing regions are estimated to be unintended [6].The prevalence of unintended pregnancy is about $34 \%$ among college students in china [10]. Among female students of Ethiopian universities and colleges it is $6.6 \%$ [11]. Early pregnancy or marriage accounts for school dropout among an estimated $5 \%$ to $33 \%$ of girls aged 15 to 24 in some countries [12]. This is also a problem among female students in Ethiopian universities [13, 14].

The rate of premarital sex among university or college students is on the rise globally and it varies from country to country. In Iranthe rate of premarital sex is $15.1 \%$ among non-medical students of a great university of Mashhad, which was more common among males than females [15].In southern Iran (in Shiraz) the rate of premarital sex among the youth is $47.5 \%$ [16]. It is $63.9 \%$ among the unmarried youth of Vientiane Capital City, with higher prevalence among males than females [17].It is $8.1 \%$ among unmarried female undergraduates in China (Wuhan) $[5,18]$.The rate of premarital sexual intercourse was low (4.3\%) among students of Dicle University in Turkey, it being more prevalent among males than females ( $87.7 \%$ and $44.2 \%$ respectively) [19].The prevalence of premarital sexual practice in Africa seems to be higher compared to other continents. A very recent study conducted in Nigeria showed that the prevalence of premarital sex was $45.8 \%$ among nursing students, with more frequency among male students [20]. A study published in 2014 showed a high prevalence of premarital sex (70.4\%) among female undergraduates' students of Muhimbili and Dar es Salaam Universities, Tanzania [21]. It was very high in Uganda (74\%) andBostwana (65.35\%) as indicated by a study published in 2010and 2012, respectively. In Ethiopia the prevalence of premarital sex among university or college students ranges from about $23 \%$ to $68 \%$ [22-35].

Several studies have shown that premarital sex (having sex before the age of 18) is common in Ethiopian its prevalence varies from one university to another. It was found to be $57.6 \%$ for MizanAman College of Health Science, 37.9\% for Asksum University, 47.6\% for private colleges in Bahir Dar, 24.3\% for Bahir Dar Universityand $23.6 \%$ for University of Gondar (23.6\%)[23, 29, 36-38]. In Ethiopia premarital sex is 
associated with several factors including gender, watching pornography, alcohol use, attending night clubs, khat chewing $[22,25,39,40]$.

Having sex with multiple (two or more) partners also shows variations among universities:Aksum university (64.4\%), University of Gondar (54.2\%), private colleges in Bahir Dar (45.3\%) and Bahir Dar University (42.7\%), Madawalabu university (33.6\%), governmental higher institution in Debre Markos (33.2\%), Wollega university (31.3\%), private colleges in Mekelle (30.5\%),Jigjiga university (30.14\%), Debre Berhan university (21.4\%) andMizan Aman College of Health Sciences (16.3\%)[22-25, 29, 31, 33, 36-38, 41]. Unprotected sex can reach upto $62 \%$ as reported for students of Bahir Dar university [23], and it may be association with alcohol intake [36].

There are no or a few published reports on the prevalence ofpremarital unsafe sex among students of private colleges such as ATHSBC. The aim of this study was therefore to determine the prevalence of unsafe premarital sex and associated factors among students of ATHSBC.

\section{Methods}

\section{Study area}

ATHSBC, located in Addis Ababa, capital of Ethiopia, was established in 2007 as a health science college and later included business departments in its academic programs. The college runs degree and level programs (level I to IV) in regular and extension modalities. During the study period, there were a total of about 2900 students in regular and extension divisions.

\section{Study design and period}

A cross-sectional survey was conducted among ATHSBC students from April to May, 2019.

\section{Source population}

The source population was all students (regular and extension) of ATHBC.

\section{Study Subjects}

Randomly selected unmarried students participated in the study.

\section{Sampling methods and procedure}

Systematic random sampling was used to select 422 students from the source population of about 2900 students.

\section{Sample size}

Sample size (n) is calculated to be 380 using single population proportion formula and $50 \%$ proportion of premarital sex from a previous study. 
$n=z^{2} p(1-p) / w^{2}$

where,

$p=$ proportion $(50 \%)$

$\mathrm{n}$ = sample size

$z=$ confidence interval (with 95\% level of certainty)

$w=$ margin of error $(5 \%)$

When $10 \%$ non-response rate is considered, the sample size became 422.

\section{Inclusion and exclusion criteria}

Unmarried students were included, whereas married students were excluded.

\section{Study variables}

The independent variables were sex, age, religion, and frequency of religious service attendance, field of specialization, education level of parents, place of residence, cohabitant type and place of high/preparatory school completion.

Dependent variable consisted of having sex, having sex without condom, frequency of condom use, having given/received benefit for sex, knowledge of STIs of a new sexual partner, having seen pornography, having drunk alcohol, knowledge of effect of unsafe sex, and occurrence of pregnancy and abortion.

\section{Data collection and analysis}

Data was collected from study participants by using self-administered close ended questionnaire. To validate the questionnaire, a pretest survey was done among 20 students of a different private health and business college.Data was entered into Excel before export to SPSS v20 for data management and analysis. Associations between variables were determined by comparing proportions usingchi-square test or Fisher's exact test. P-value less than 0.05 was considered statistically significant.

\section{Results}

\section{Socio-demographic characteristics of the study participants}

The socio-demographic characteristics of the study participants are presented in Table 1. Out of 422 single students recruited to take part in this study, 390 students filled the questionnaire, giving a response rate of $92.4 \%$.The majority of the participantswere $18-21$ years old (61\%), females (81\%), Christians (61.6\%), business students (58.8\%), degree students (56.8\%), regular students (62.1\%) and first year 
students (49.1\%). Most of them lived together with both parents (35.6\%), did not have income (69\%), lived in and around Addis Ababa for five or more years (63.7\%), and completed grade 10 or 12 in and around Addis Ababa (55.7\%). The majority of the respondents reported that their mothers are uneducated $(34.1 \%)$ or have primary education $(30.7 \%)$, and that their fathers have primary $(31.1 \%)$ or secondary (23.1\%) education. For the majority, mothers and fathers were housewives (50.8\%) and self-employed (33.6\%), respectively.

Table 1. Socio-demographic characteristics 


\begin{tabular}{|c|c|c|c|}
\hline Variable & Measurement level & Frequency & Percent \\
\hline Sex & Male & 74 & 19.0 \\
\hline Female & 316 & 81.0 & \\
\hline Age & $16-17$ & 22 & 5.7 \\
\hline $18-19$ & 128 & 32.9 & \\
\hline $20-21$ & 113 & 29.0 & \\
\hline $22-23$ & 65 & 16.7 & \\
\hline $24-25$ & 37 & 9.5 & \\
\hline 26 and above & 24 & 6.2 & \\
\hline Religion & Orthodox & 221 & 58.0 \\
\hline Islam & 90 & 23.6 & \\
\hline Protestant & 60 & 15.7 & \\
\hline Catholic & 1 & 0.003 & \\
\hline Other & 9 & 2.4 & \\
\hline Frequency of religious service attendance & Daily & 99 & 25.6 \\
\hline 1-2 times per week & 126 & 32.6 & \\
\hline 3 times or more per week & 74 & 19.1 & \\
\hline Occasionally & 78 & 20.2 & \\
\hline Never & 10 & 2.6 & \\
\hline Ethnicity & Amhara & 129 & 34.6 \\
\hline Oromo & 66 & 17.7 & \\
\hline Tigray & 14 & 3.7 & \\
\hline Gurage & 79 & 21.2 & \\
\hline Silte & 16 & 4.3 & \\
\hline Other & 69 & 18.5 & \\
\hline Field of study & Health & 160 & 41.2 \\
\hline Business & 228 & 58.8 & \\
\hline Total & 388 & 100.0 & \\
\hline Program of study & Level & 168 & 43.2 \\
\hline
\end{tabular}




\begin{tabular}{|c|c|c|c|}
\hline Degree & 221 & 56.8 & \multirow[b]{2}{*}{62.1} \\
\hline Division of study & Regular & 242 & \\
\hline Extension & 148 & 37.9 & \multirow[b]{2}{*}{49.1} \\
\hline Year of study & First & 191 & \\
\hline Second & 85 & 21.9 & \multirow[b]{4}{*}{31.0} \\
\hline Third & 61 & 15.7 & \\
\hline Fourth & 52 & 13.4 & \\
\hline Have income & Yes & 115 & \\
\hline No & 256 & 69.0 & \multirow[b]{2}{*}{35.7} \\
\hline Type of cohabitant & Both parents & 138 & \\
\hline Mother & 48 & 12.4 & \multirow[b]{9}{*}{55.7} \\
\hline Father & 8 & 2.1 & \\
\hline Brother & 40 & 10.3 & \\
\hline Sister & 50 & 12.9 & \\
\hline Other relatives & 58 & 15 & \\
\hline Guardian & 3 & .8 & \\
\hline Friend & 4 & 1.0 & \\
\hline None (Alone) & 38 & 9.8 & \\
\hline Place where Grade10 or 12 Completed & In or around Addis Ababa & 215 & \\
\hline Amhara & 61 & 15.8 & \multirow[b]{6}{*}{23.8} \\
\hline Oromia & 50 & 13.0 & \\
\hline Debub (South) & 47 & 12.2 & \\
\hline Tigray & 6 & 1.6 & \\
\hline Other & 7 & 1.8 & \\
\hline Number of years lived in or around Addis Ababa & $1-2$ years & 92 & \\
\hline $3-4$ years & 48 & 12.4 & \multirow{4}{*}{34.1} \\
\hline 5 years and above & 246 & 63.7 & \\
\hline Education of mother & Uneducated & 130 & \\
\hline Primary & 117 & 30.7 & \\
\hline
\end{tabular}




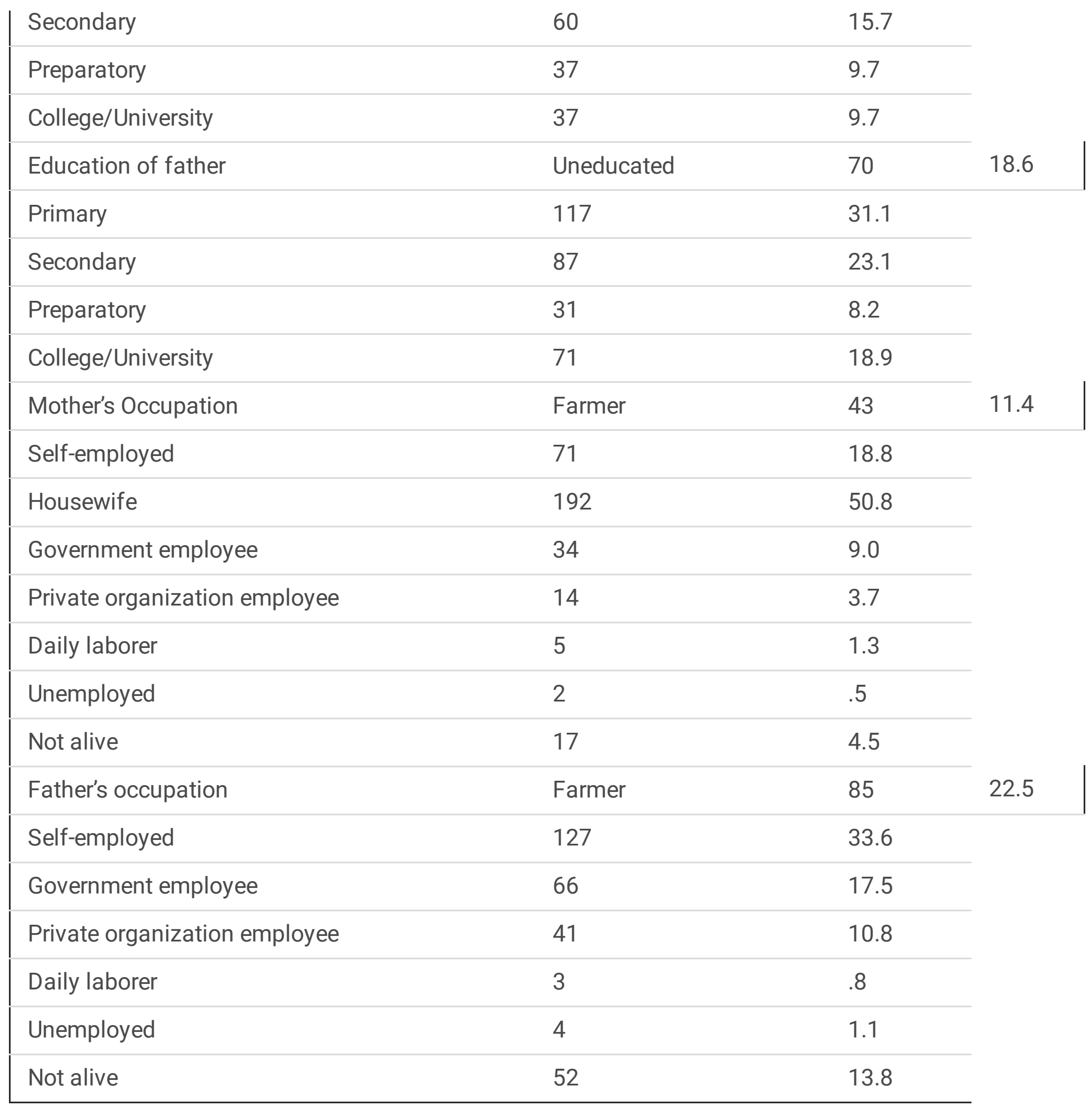

\section{Prevalence of pre-marital sex}

The prevalence of premarital sex was $23.3 \%$ (88/378)among the study participants, of which $43.5 \%$ had sex in the last 12 months, $14.3 \%$ (12/84) were homosexuals, and $7.1 \%$ received gift or money and $7.4 \%$ gave in exchange for sex. Regarding recent sexual history, $11.4 \%$ of the participants responded that they had sex in the last 12 months.A very small proportion (3.4\%) of the respondents said that they practiced homosexuality. This accounts for $14.3 \%(12 / 84)$ of those who had practiced premarital sex. Nine of the 12 were females. For about $61 \%$ of those who had experienced premarital sex, the first sexual partner was 
a student. The most common reasons reported for starting sex before marriage was fall in love (69.3\%), development of sexual desire (12\%) and peer pressure (9.3\%).

Chi square test revealed that premarital sex prevalence showed significantly increasing trend from $12.7 \%$ $(16 / 126)$ in the age group $18-19$ to $52.2 \%(12 / 23)$ in the age group 26 and higher $(P=0.000)$. Chi square test also showed the prevalence of premarital sex is statistically significantly related to sex, religion, frequency of religious service attendance, field of study, division of study, study program, income, living habit, place grade 10 or 12 is completed, number of years lived in Addis Ababa and its surroundings, having boy-or girlfriend, seducing opposite sex, misconception about the use of contraceptive pills, watching porn, taking alcohol or other drugs (Table 2). In this regard, the current study revealed that premarital sex was more common among males, Christians, health students, degree students and nonregular students (Table 2). It was also more frequent among study participants whohave never attend religious services and those who attend occasionally, who had income, who live alone, who completed grade 10 or 12 outside Addis Ababa or its surrounding, lived in Addis Ababa for a few years, who watch porn, who responded contraceptive pills provide protection against STIs, who take alcohol, who take drugs, who seduce opposite sex, and who have boy-or girl-friend (Table 2).

Table 2. Prevalence of premarital sex among subgroups of the study participants 


\begin{tabular}{|c|c|c|c|c|}
\hline Variable & Measurement level & Frequency & Percent & P-value \\
\hline Sex & Male & $30 / 72$ & $41.7 \%$ & 0.000 \\
\hline Female & $58 / 306$ & $19 \%$ & & \\
\hline Religion & Christian & $76 / 272$ & $27.9 \%$ & 0.000 \\
\hline Muslim & $7 / 90$ & $7.8 \%$ & & \\
\hline Religious service attendance & $\begin{array}{l}\text { Daily to one or more } \\
\text { times per week }\end{array}$ & $49 / 290$ & $16.9 \%$ & 0.000 \\
\hline Occasional & $33 / 76$ & $43.4 \%$ & & \\
\hline Never & $6 / 9$ & $67.7 \%$ & & \\
\hline Field of study & Health & $52 / 158$ & $32.9 \%$ & 0.000 \\
\hline Business & $36 / 218$ & $16.5 \%$ & & \\
\hline Program of study & Level & $20 / 162$ & $12.3 \%$ & 0.000 \\
\hline Degree & $68 / 215$ & $31.6 \%$ & & \\
\hline Division of study & Regular & $43 / 239$ & $18 \%$ & 0.001 \\
\hline Non-regular & $45 / 139$ & $32.4 \%$ & & \\
\hline Have income & Yes & $39 / 109$ & $35.8 \%$ & 0.000 \\
\hline No & $44 / 252$ & $17.5 \%$ & & \\
\hline Living habit & With others & $71 / 338$ & $21 \%$ & 0.002 \\
\hline Alone & $16 / 37$ & $43.3 \%$ & & \\
\hline PlaceGrade10 or 12 Completed & $\begin{array}{l}\text { Addis Ababa and its } \\
\text { surrounding }\end{array}$ & $34 / 209$ & $16.3 \%$ & 0.000 \\
\hline $\begin{array}{l}\text { Out of Addis Ababa and its } \\
\text { surrounding }\end{array}$ & $52 / 158$ & $32.9 \%$ & & \\
\hline $\begin{array}{l}\text { Number of years lived in Addis } \\
\text { Ababaand its surrounding }\end{array}$ & $1-2$ years & $28 / 87$ & & 0.044 \\
\hline $3-4$ years & $13 / 47$ & & & \\
\hline 5 years and above & $47 / 241$ & & & \\
\hline Seduce opposite sex & Yes & $14 / 19$ & $73.7 \%$ & 0.000 \\
\hline NO & $68 / 261$ & $20.7 \%$ & & \\
\hline Have boy-/girl-friend & Yes & $65 / 145$ & $44.8 \%$ & 0.0000 \\
\hline No & $21 / 217$ & $9.7 \%$ & & \\
\hline
\end{tabular}




\begin{tabular}{|lllll|}
\begin{tabular}{|l} 
Do contraceptive pillsprovide \\
protection against STIs?
\end{tabular} & Yes & $26 / 49$ & $53.1 \%$ & 0.000 \\
\hline No & $54 / 278$ & $19.4 \%$ & & \\
\hline Ever seen Pornography & Yes & $29 / 84$ & $34.5 \%$ & 0.000 \\
\hline NO & $31 / 273$ & $11.4 \%$ & & \\
\hline Take alcohol & Yes & $36 / 60$ & $60 \%$ & 0.000 \\
\hline No & $49 / 301$ & $16.3 \%$ & & \\
\hline Use drug & Yes & $7 / 10$ & & $\begin{array}{l}\text { (.002, } \\
\text { (Fisher's } \\
\text { Exact }\end{array}$ \\
\hline No & & & & Test) \\
\hline
\end{tabular}

\section{Risky behaviors}

\section{Early premarital sex}

Although some students (21\%), started sexual intercourse early before the age of 18 , nearly three-quarters (76.6\%) began to test sex between the age of 18 and 23 , inclusively. The great majority ( $86.4 \%)$ of the students started to experience sexual intercourse in college (37\%), preparatory school $(25.9 \%)$ and secondary school (23.5\%). Most of them (61.4\%) responded that their first sexual partner wasa student.Almost half $(48.8 \%)$ of those who had a history of premarital sex did not plan for the first sexual intercourse, and most of them (68.2\%) performed unprotected first sexual intercourse.

Early sex (before 18$)$ was found to be more prevalent among males $(35.7 \% ; 10 / 28)$ than females $(18.8 \%$; $8 / 58)(p=0.019)$.

\section{Unprotected premarital sex}

Among those who hada history of sexual intercourse, regardless of whether it was the first sex or not, $70 \%(49 / 70)$ had a history of having sex without condom, and $47.3 \%$ (35/74) have never used condom for sex. About $68 \%$ did not use condom for the first sex. The most common reasons reported for having sex without condom werethinking that they had sex accidentally and I did not have condoms with them (40\%), and that they believed that their new sexual partner is STIs-free (26.3\%) (Table 3). History of unprotected sex was more common among degree students $(76.4 \%)$ compared to level students (33.3\%) $(\mathrm{p}=0.000)$, and among those who have ever seen pornography $(78.6 \% ; 22 / 28)$ compared to those who did $\operatorname{not}(54.5 \%$; 30/55) (p- 0.032).

\section{Having multiple sexual partners and multiple boy-/girl friends}


Out of 82 respondents, 28 (34.1\%) had two or more lifetime sexual partners, of whom $6(21.4 \%)$ had five or more lifetime sexual partners. Out of those who had a history of sexual intercourse $7.3 \%$ had five or more sexual partners in their life time.Out of 58 respondents, $15.5 \%$ had two or more current sexual partners (44.4\% (4/9) of whom had five or more current partners), and only $6.9 \%$ had five or more current sexual partners. Having multiple sexual partners ( 2 or more partners) is more frequent among degree students $(40.6 \% ; 26 / 64)$ than level students $(11.1 \% ; 2 / 18)(p=0.020)$; among those who do not have a habit requesting a new sexual partner for HIV test result $(47.4 \% ; 18 / 38)$ compared to those who do so $(21.4 \% ; 6 / 28$ ( $p=0.03$, and among those who drink alcohol $(47.2 \% ; 17 / 36)$ than those who do not $(25 \%$; $11 / 44)(p=0.038)$. Moreover, those who seduce opposite sex tend to have multiple sexual partners. The most common reasons reportedfor having multiple sexual partners was conflict $(27.3 \%)$ and to get a partner that provides a better sexual satisfaction (13.6\%).

About $41.2 \%$ (153/371) reported to have a body/girlfriend and $15 \%(23 / 153)$ had 2 or more boy/girlfriends. From 145 respondents who had a body/girlfriend, 65 (75.6\%) reported that they had a history of premarital sex.

\section{Having sex with a person with unknown HIV status}

Nearly three-fifth $(58.8 \% ; 47 / 80)$ respondents have a tendency of establishing a new sexual partner without asking for HIV test result.Requesting a new sexual partner for HIV test result was found to be more frequent among females $(53.7 \% ; 29 / 54)$ thanamong males $(15.4 \% ; 2 / 26)(p=0.001)$;among those who planned the first sex $(58.8 \% ; 20 / 340$ compared to those who did not $(27.3 \% ; 9 / 33)(P=0.009)$, and among those who have one lifetime sexual partner $(52.4 \% ; 22 / 42)$ compared to those who have multiple partners (two or more) $(25 \% ; 6 / 24)(P=0.03)$. But it was less common among those who have ahistory of watching pornography $(24.1 \% ; 7 / 29)$ than those who do not $(53.1 \% ; 23 / 49)(p=0.012)$.

The most requent reasons reported for not requesting a new sexual partner for HIV test result were thinking that the new partner is HIV-free (37.3\%), not remembering about the question (28.8\%), lack of knowledge that they had to ask the question (16.9\%) and being careless $(16.9 \%)$.

\section{Seducing opposite sex}

Out of 356 respondents, 19 (5.3\%) said that they had a history of seducing opposite sex in some way.Seducing tends to be more common among those who aged 20 and above $(0.7 \% ; 1 / 141)$ compared to those who are less than $20(8.4 \% ; 18 / 215)(p=0.002)$.Seducing is more common among health students $(9.6 \% ; 14 / 146)$ compared to business students $(2.4 \% ; 5 / 208)(p=0.003)$.Fisher's Exact Test showed that seducing is more common among those who received gift or money for sex $(66.7 \% ; 4 / 6)$ compared to those who do not $(8.9 \% ; 9 / 101)(p=0.002)$; among those who had a history of STIs $(42.9 \%$; $3 / 7)$ compared to those who did not $(4.3 \% ; 15 / 346)(p=0.003)$; among those who believe that contraceptivepillsprevent STIs $(17 \% ; 8 / 47)$ compared to those who do not $(3.6 \% ; 10 / 275)(p=0.002)$; among those who drink alcohol $(22.4 \% ; 13 / 58)$ than those who do not $(1.7 \% ; 5 / 295)(p=0.000)$; among 
those who use drug $(40 \% ; 4 / 10)$ than those who do not $(4.1 \% ; 14 / 341)(p=0.001)$; among those who have a history of watching pornography $(25.8 \% ; 16 / 62)$ than those who do not have $(0.7 \% ; 2 / 290)(p=0.000)$.

\section{Watching pornography}

Many participants $(17.3 \%, 63 / 365)$ responded that they had a history of watching pornography, of which $6.3 \%(4 / 63)$ were addicted toitand $23.8 \%(15 / 63)$ watch it most of the time.Watching pornographywas more common among males $(37.7 \% ; 26 / 69)$ than females $(12.5 \% ; 37 / 296)(p=0.000)$; among those who have history of premarital sex $(34.5 \% ; 29 / 84)$ than those who do not $(11.4 \% ; 31 / 273)(p=0.000)$; among those who had sex in the last 12 months $(45 \% ; 18 / 40)$ than those who do not $(13.2 \% ; 39 / 296)(p=0.000)$; among those who have history of having sex without condom $(42.3 \% ; 22 / 52)$ than those who do not $(19.4 \% ; 6 / 31)(p=0.032)$; among those who have never requested a new sex partner for HIV test result $(48.9 \% ; 22 / 45)$ than those who have done so $(21.2 \%$; $7 / 33)(p=0.012)$; among those who have boy/girlfriend $(23.1 \%$; 33/143) than those who do not $(13.2 \% ; 29 / 220)(p=0.014)$; among those who believe that contraceptive pills prevent STIs $(29.8 \%$; $14 / 47)$ compared to those who do not $(15 \% ; 42 / 280)$ $(p=0.013)$, and among those who drink alcohol $(41.7 \% ; 25 / 60)$ than those who do not $(11.9 \% ; 36 / 302)$ $(p=0.000)$.Fisher's exact test showed that watching pornography is also more frequent among those who seduce opposite sex $(88.9 \% ; 16 / 18)$ than those who do not $(13.8 \% ; 46 / 334)(P=0.000)$.

\section{Taking alcohol and other drugs}

About 17\% (63/369) of the study participants reported that they drink alcohol. Alcohol drinking was more common among males $(36.2 \% ; 25 / 69)$ than females $(12.7 \% ; 38 / 300)(p=0.000)$; among those who have income $(29.2 \% ; 31 / 106)$ than those who do not $(11.8 \% ; 29 / 245)(p=0.000)$; among those who have a history of premarital sex $(42.4 \% ; 36 / 85)$ than those who do not $(8.7 \% ; 24 / 276)(p=0.000)$; among those who believe that contraceptive pills prevent STIs $(37.5 \% ; 18 / 48)$ than those who do not $(14.1 \% ; 40 / 284)$ $(p=0.000)$; among christians $(36.2 \% ; 57 / 265)$ thanmuslims $(3.4 \% ; 3 / 87)(p=0.000)$, and among those who have a history of watching pornography $(41 \% ; 25 / 61)$ than those who do not $(11.6 \% ; 35 / 301)(p=$ 0.000). It was also more common among those who have multiple sexual partners in their lifetime (36.5\%; $19 / 52)$ than those that have one partner $(60.7 \% ; 17 / 28)(p=0.038)$. Three percent of the respondents said that they took drugs.

Table 3. Risky behaviors 


\begin{tabular}{|c|c|c|c|}
\hline Variable & Measurement level & Frequency & Percent \\
\hline Ever had sex & Yes & 88 & 23.3 \\
\hline No & 290 & 76.7 & \\
\hline Age at first sex & $12-13$ & 4 & 4.7 \\
\hline $14-15$ & 5 & 5.8 & \\
\hline $16-17$ & 9 & 10.5 & \\
\hline $18-19$ & 31 & 36.0 & \\
\hline $20-21$ & 21 & 24.4 & \\
\hline $22-23$ & 14 & 16.3 & \\
\hline $24-25$ & 2 & 2.3 & \\
\hline Grade at first sex & Grade 5-6 & 5 & 6.2 \\
\hline Grade 7-8 & 6 & 7.4 & \\
\hline Grade 9-10 & 19 & 23.5 & \\
\hline Grade $11-12$ & 21 & 25.9 & \\
\hline College student & 30 & 37.0 & \\
\hline First sex partner & Maid Servant & 3 & 5.3 \\
\hline Commercial sex worker & 2 & 3.5 & \\
\hline Student & 35 & 61.4 & \\
\hline Teacher & 5 & 8.8 & \\
\hline Business man & 6 & 10.5 & \\
\hline Unknown person & 3 & 5.3 & \\
\hline Relative & 3 & 5.3 & \\
\hline Used condom at first sex & Yes & 27 & 31.8 \\
\hline No & 58 & 68.2 & \\
\hline Reason for premarital sex & Fell in love & 52 & 69.3 \\
\hline Peer pressure & 7 & 9.3 & \\
\hline Developed desire for sex & 12 & 16.0 & \\
\hline Raped & 2 & 2.7 & \\
\hline Drunk & 1 & 1.3 & \\
\hline
\end{tabular}




\begin{tabular}{|c|c|c|c|}
\hline Opposite sex seduced me & 1 & 1.3 & \\
\hline First sex planned & Yes & 39 & 48.8 \\
\hline No & 41 & 51.3 & \\
\hline Had Sex in the last 12 months & Yes & 40 & 11.4 \\
\hline No & 312 & 88.6 & \\
\hline Received gift for sex & Yes & 6 & 5.2 \\
\hline No & 109 & 94.8 & \\
\hline Gave gift for sex & Yes & 7 & 6.7 \\
\hline No & 98 & 93.3 & \\
\hline Number of Lifetime sex partners & 1 & 54 & 65.9 \\
\hline 2 & 12 & 14.6 & \\
\hline 3 & 7 & 8.5 & \\
\hline 4 & 3 & 3.7 & \\
\hline 5-10 & 4 & 4.9 & \\
\hline Above 10 & 2 & 2.4 & \\
\hline Number of current sex partners & 1 & 49 & 84.5 \\
\hline 2 & 3 & 5.2 & \\
\hline 4 & 2 & 3.4 & \\
\hline $5-10$ & 3 & 5.2 & \\
\hline Above 10 & 1 & 1.7 & \\
\hline Reason for multiple sex partners & To get a person who satisfies me better & 3 & 13.6 \\
\hline To get good looking person & 2 & 9.1 & \\
\hline To get matured person & 1 & 4.5 & \\
\hline To get more (better) benefit & 2 & 9.1 & \\
\hline $\begin{array}{l}\text { It is boring to have only one } \\
\text { sexual partner. }\end{array}$ & 2 & 9.1 & \\
\hline Due to conflict/disagreement & 6 & 27.3 & \\
\hline Other reasons & 6 & 27.3 & \\
\hline Frequency of Condom usage & Never & 63 & 60.0 \\
\hline Sometimes & 31 & 29.5 & \\
\hline
\end{tabular}




\begin{tabular}{|c|c|c|c|}
\hline Always & 11 & 10.5 & \\
\hline Ever had sex without condom & Yes & 52 & 61.2 \\
\hline No & 33 & 38.8 & \\
\hline $\begin{array}{l}\text { Reason for having sex without } \\
\text { condom }\end{array}$ & $\begin{array}{l}\text { The sex was accidental and I did not } \\
\text { have condoms with me. }\end{array}$ & 18 & 40.0 \\
\hline $\begin{array}{l}\text { I believed that my sex partner is } \\
\text { free from STls. }\end{array}$ & 12 & 26.7 & \\
\hline My sex partner refused. & 6 & 13.3 & \\
\hline $\begin{array}{l}\text { I did not know that I have to use } \\
\text { condom. }\end{array}$ & 2 & 4.4 & \\
\hline To get better sexual satisfaction & 2 & 4.4 & \\
\hline Other & 5 & 11.1 & \\
\hline $\begin{array}{l}\text { Ever requested a new sex partner } \\
\text { for HIV test }\end{array}$ & Yes & 33 & 41.3 \\
\hline No & 47 & 58.8 & \\
\hline $\begin{array}{l}\text { Reason for not requesting HIV } \\
\text { test }\end{array}$ & I did not know that I have to do that. & 10 & 16.9 \\
\hline I did not remember to do that. & 17 & 28.8 & \\
\hline I do not care about it. & 10 & 16.9 & \\
\hline $\begin{array}{l}\text { I believed that my sex partner is } \\
\text { free from STls. }\end{array}$ & 22 & 37.3 & \\
\hline Seduce opposite sex & Yes & 19 & 5.3 \\
\hline No & 337 & 94.7 & \\
\hline $\begin{array}{l}\text { Frequency of pornography } \\
\text { watch }\end{array}$ & Always & 4 & 1.1 \\
\hline Most of the time & 15 & 4.1 & \\
\hline Sometimes & 44 & 12.1 & \\
\hline Never & 302 & 82.7 & \\
\hline Ever had homosex & Yes & 12 & 3.3 \\
\hline No & 352 & 96.7 & \\
\hline Drink alcohol & Yes & 63 & 17.1 \\
\hline No & 306 & 82.9 & \\
\hline Take Drugs & Yes & 11 & 3.0 \\
\hline
\end{tabular}




\section{Factors associated factors with premarital sex}

Chi square test revealed that the prevalence of premarital sex is statistically significantly associated with sex, religion, frequency of religious service attendance, field of study, division of study, study program, income, living habit, place grade 10 or 12 is completed, number of years lived in Addis Ababa and its surroundings, having boy-or girlfriend, seducing opposite sex, misconception about the use of contraceptive pills, watching porn, taking alcohol or other drugs (Table 2).

\section{Consequences of unsafe premarital sex}

About $4.7 \%(13 / 275)$ female respondents or $20 \%(13 / 65)$ of females who had a history of premarital sex said that they had experienced unintended pregnancy. $6 / 13$ experienced 2 or more pregnancies. 6/13 committed abortion. $26 / 33$ females responded that they committed 3 or more abortions. The prevalence of self-reported STIs was 1.9\% (7/359). Among those who practiced sexual intercourse, $5.9 \%(5 / 85)$ had history of STIs, including HIV.

\section{Misconception about oral contraceptive pills}

Out of 332 respondents, 48 (14.5\%) said that oral contraceptive pills provide protection against STIs. This misconception was more common among those who drink alcohol than those who do not $(10.9 \%)$ $(30 / 274)(p=0.000)$; who have a history of watching pornography $(12.2 \% ; 33 / 271)$ compared to those who do not $(25 \% ; 14 / 56)(p=0.013)$; who have a history of having premarital sex $(32.5 \% ; 26 / 80)$ compared to those who do not $(9.3 \% ; 23 / 247)(p=0.000)$; whose mothers are uneducated or have primary education $(11.7 \% ; 25 / 214)$ than those whose mothers have secondary education and above $(20.4 \%$; 23/113) $(p=0.035)$.

\section{Discussion}

The present study investigated the prevalence of premarital sex and risky sexual practices (behaviors) among students of a private college. It revealed the prevalence premarital sexual intercourse among the study participants, which was $23.3 \%$, is lower than the recentlyreported figures for students of governmental higher institutions in Ethiopia, including Robe Technical and Vocational Education Training College (51.9\%) [35], Aksum University (60\%) [29], private colleges in Mekelle (51.9\%) [33], Addis Ababa Science and Technology University (26.8\%)[27], Wollega University $(28.4 \%, 36.4 \%)[25,26]$, Jigjiga University (67.67\%)[24], Debre Tabor university (25.9\%) [30], Debre Markos government higher education institutions (25.\%)[41] Addis Ababa University (26.8\%)[27]and Debre Berhan University (54.3\%)[22], and private colleges in Mekelle (51.9\%) [33]. The current figure is also lower than the ones reported for nursing students from healthcare training institutions in Enugu State (45.8\%) of Nigeria [20], forfemale undergraduates' students of Muhimbili and Dar es Salaam Universities(70.4\%), Tanzania[21], for students of Uganda Martyrs University (74\%) [42] and for students of Botswana University (65.35\%)[43] as 
indicated by a study published in 2010 and 2012, respectively. These differences may be due to the fact that students of governmentuniversities have greater freedom to practice sexual intercourse compared to private colleges since they live in universities where parents or close relatives cannot have control over them, and where the society in which they grew up cannot see them. About 90 percent of our study participants live with parents or close relatives, and thus it might have not be easy for them to engage in sexual practice (Table 1). This could be the reason why we found that premarital sex was common among those who live alone than those who live together with parents or relatives (Table 2), and this finding is consistent with that of governmental higher institution in Debre Markos Town in Ethiopia [41].

However, it is greater than that of non-medical students of an Iranian university, called a great university of Mashhad (15.1\%) [15], female undergraduates inWuhan (8.1\%), China [5, 18], and students of Dicle University (4.3\%) in Turkey [19].This discrepancy could be explained by religious differences. In Iran and Turkey the dominant religion is Islam which does not only forbids premarital sex practice but also punishes the act. In Ethiopia, the predominant religion is Christianity, which forbids but does not punish premarital sexual practice, which may let considerably a large number of adolescents get a gap to practice premarital sexual practices. This same reason may also explain our finding that premarital sex was common among Christians than among Muslims (Table 2), suggesting that religion and religiosity can play an important role in whether or not adolescent practice premarital sexual intercourse[2, 4]. Religiositydifference may also explain our finding of higher prevalence of premarital sex among study participants who attend religious servicesdaily to one or more times per week (16.9\%) compared to those who do so occasionally (43.4\%) and those who never attend at all (67.7\%) (Table 2), which is consistent with a study done among students governmental higher institution in Debre Markos Town [41].

Our finding that premarital sex is more frequent in males than females is in consistent with studies conducted among students of Robe Technical and Vocational Training College, Wollega University, Haramaya University and Debre Berhan university in Ethiopia [22, 25, 34, 35], among nursing students in Nigeria [20], among non-medical students of a great university of Mashhad in Iran[15], and among students of Dicle University in Turkey [19]. The greater frequency of premarital sex among males compared to females could be for several reasons. Males usually dare to ask females for sex, watch pornography, drink alcohol, participate in night clubs, and care much less about maintaining virginity than females do.

In this study it was found out that premarital sex is common among health students (nursing and public health) compared to business students. Since health students take courses about reproductive health and reproductive organs anatomy, class lessons about this may stimulate students to decide to get involved in more sexual practices compared to business students.

Similarly, the prevalence of premarital sex was found to be higher in degree students compared to level students. The reason for this might be age difference between level students and degree students, and the age categories at which premarital sex is more prevalent. Level students are generally younger than degree students. About $72 \%$ of level students who participated in this study were less than 20 years of 
age, whereas about $76 \%$ degree student whose age was 20 and above took part in this study $(p=0.000)$. Premarital sex was more prevalent at and above the age of 20 (Table 2).

The present finding that premarital sex prevailed among non-regular students compared to regular students could be due to being greater or equal to 20 years of age, both of which contribute to having premarital sex. About $80 \%$ of non-regular students who participated in this study were aged 20 or above, whilst about one-half of regular students study participant were in this age range $(p=0.000)$.As mention above, premarital sex was more prevalent at and above the age of 20 (Table 2).

Likewise, our study showed premarital sex was more common among students that have income compared to those who do not have. Getting involved in sexual practice might poseexpenses (travel, hotel, refreshment and other related expenses) which student who have income can afford to pay. Moreover, having income may reduce financial stress. Therefore in the presence of income and reduced stress student may have increased interest for practicing sexual intercourse.

The finding that premarital sex was more common among those students who completed grade 12 or 10 outside Addis Ababa and its surrounding compared those who completed in and around Addis Ababa may be due that fact that most (84\%) of the former group live alone, which endows them with the freedom or privacythat makes it easier for them to have sexual intercourse.In addition to freedom, living alone may reduce hotel and travel expenses that would have otherwise made sexual practice unaffordable.

Our study revealed that the prevalence of premarital sex was higher in those who seduce opposite sex than those who do not. This was expected since the purpose of seducing to stimulate opposite sex to have sex with.

Premarital sex was also found to be more frequent among those who believe that oral contraceptive pills provide protection against STIs including HIV. Because of this wrong belief they might have thought that the can avoid the two major consequences (pregnancy and contraction o STIs) of having premarital sex by taking contraceptive pills.

The finding of the current study that premarital sex was common among alcohol and drug users than non-users is consistent with a similar study conducted among Robe Technical and Vocational Training College, Wollega university, Bahir Dar university and governmental higher institution in Debre Markos in Ethiopia $[23,25,35,41]$, it might be explained by tendencies of people to do sexual intercourse after taking these substances since they can affect decision making of a person.

Our result that premarital sex was more common among those participants who had girl/boy-fried than those who did not have suggests that the purpose establishing girl/boy fried might be to have sexual intercourse.

Our finding that premarital sex is more common among those students who watch pornography than those who do not is in agreement with a similar study conducted among students of Debre Berhan and 
Bahir Dar Universities [22, 23]. The effect of watching pornography on premarital sexual practice is also evident among high school students in Ethiopia [39, 40,44]. The most probable reason for higher frequency of premarital sex among pornography watchers is that watching pornography stimulates them to have sex.

In the present study, the majors reasons reported for having premarital sex was fall in love and fulfilling sexual desire, and this is in agreement with the finding fromstudents of governmental higher institution in DebreMarkos Town , Ambo University andDebre Tabor University [14, 30, 41].

In this study the prevalence of early premarital sex (having sex before the age of 18 ) was $21 \%$, which is lower than that of students of Mizan Aman College of Health Science (57.6\%), Asksum university (37.9\%), private colleges in Bahir Dar (47.6\%), Bahir Dar University (24.3\%) and University of Gondar (23.6\%)[23, 29, 36-38]. This might be due to differences in cultural background from which students come. Our finding that early premartital sex was found to be common among boys than girls is consistent with that of Haramaya University students[34].

In the present study $34.1 \%$ of study participants reported to have two or more sexual partners which is less than that of students of Aksum University (64.4\%), University of Gondar (54.2\%), private colleges in Bahir Dar (45.3\%) and Bahir Dar University $(42.7 \%)[23,29,36,38]$ but greater than that of students of private colleges in Mekelle (30.5\%), Mizan Aman College of Health Sciences (16.3\%) [37], and Madawalabu, Wollega, Debre Berhan and Jigjiga universities, and governmental higher institution in Debre Markos, in which33.6\%, 31.3\%,21.4\%, 33.2\% and 30.14\%had multiple sexual partners,respectively[22, 24, 25, 31, 33, 41].

According to this study, $61.2 \%$ of those study participants who experienced sexual intercourse had ever practiced unprotected sex.This value is similar to that of students of Bahir Dar university (62\%) [23], but it is higher than that of students of private colleges in Bahir Dar (38.4\%) which also showed that having unprotect sex was association with alcohol intake as it is in our case [36]. In our study, $68.2 \%$ students who practiced premarital sex reported that they did not use condom for the first sex, and this figure is greater than that of students of Addis Ababa Science and Technology University which is 46\% [27]. This difference might be explained by variation in the level of awareness.

In the present study, $17.3 \%$ had ever watched pornography. This is lower than the figure reported for students of University of Gondar (55.5\%), Bahir Dar University (65.4\%) and Debre Berhan University $(52.6 \%)[22,23,38]$. In line with these two studies, we also found that watching pornography was common among males than females, suggesting that male students are more interested in sex than female students.

Our study showed that $17.1 \%$ students drink alcohol is similar to that of students of Mizan

Aman College of Health Science which is 17.2\% [37]. This is lower than the value reported for students of DebreTabor university, Debre Berhan university and university of Gondar which was $51.6 \%, 50.9 \%$ and 
$34.6 \%$, respectively[22, 30, 38].

The prevalence of self-reported STIS in this study was $1.9 \%$, which is lower than that of students of Godar University in which $18.2 \%$ students reported to have STIs [38]. The difference might be due to difference in being careful about avoiding consequences of unprotected sex. About $96 \%$ of our study participants knew the consequences of unprotected sex.

\section{Conclusions}

The finings of this study show that the prevalence of premartital sex and risky sexual behaviors is high among students of ATHSBC. This study also indicated that many students do care about the HIV status of new sexual partners, and some students have misconception that oral contraceptive pills prevent from STIs. Therefore, effective health education must be provided to college students in order to save them from being victims of unwanted pregrancy and STIs.

\section{Abbreviations}

ATHSBC Ayer Tena Health Science and Busines College

STIs Sexually Transmitted Infections

HIV Human Immunodeficiency Virus

\section{Declarations}

\section{Ethics approval and consent to participate}

The purpose of the study, and advantage and disadvantages of taking part in the study was explained to them. Information was obtained from study participants after their written consent to participate. Their identity was not recorded during and after the study. Ethical clearance was obtained from Ethical Review Committee of Ayer Tena Health Science and Business College (ATHSBC). Full names of committee members: Mihiretu Kumie, Atsede Feleke, Gemechu Jofiro, Gezahegn Ketema and Tsehay Mulgeta. All members were affiliated to ATHSBC.

\section{Consent for publication}

Not applicable.

\section{Availability of data and materials}

The datasets on which the current study is based are available from the corresponding author on reasonable request.

\section{Competing interests}


The authors declare that they have no competing interests.

\section{Funding}

This study is funded by Ayer Tena Health Science and Business College. It covered the cost of questionnaire duplication, data collection, analysis and manuscript writing.

\section{Authors' contributions}

DJB designed the study, collected and analysed data, and wrote the manuscript.

MK designed the study, collected and analysed data, and wrote the manuscript.

All authors have read and approved the manuscript.

\section{Acknowledgements}

Not applicable

\section{References}

1. Khalajabadi Farahani F, Cleland J: Perceived norms of premarital heterosexual relationships and sexuality among female college students in Tehran. Cult Health Sex 2015, 17(6):700-717.

2. Shirazi KK, Morowatisharifabad MA: Religiosity and determinants of safe sex in Iranian non-medical male students. J Relig Health 2009, 48(1):29-36.

3. Davidson JK, Sr., Moore NB, Earle JR, Davis R: Sexual attitudes and behavior at four universities: do region, race, and/or religion matter?Adolescence 2008, 43(170):189-220.

4. Muhammad NA, Shamsuddin K, Sulaiman Z, Amin RM, Omar K: Role of Religion in Preventing Youth Sexual Activity in Malaysia: A Mixed Methods Study. J Relig Health 2017, 56(6):1916-1929.

5. Cao Y, Xiao H, Yan H, Li J, Li S: Prevalence and sex-related risk factors of premarital pregnancy and reproductive tract infections among female undergraduates in Wuhan, China. Asia Pac J Public Health 2015, 27(2 Suppl):30S-40S.

6. Darroch J, Woog V, Bankole A, Ashford LS: Adding it up: Costs and benefits of meeting the contraceptive needs of adolescents New York: Guttmacher Institute; 2016.

7. UNFPA: Girlhood, not motherhood: Preventing adolescent pregnancy. New York: UNFPA; 2015.

8. Guo C, Pang L, Ding R, Song X, Chen G, Zheng X: Unmarried Youth Pregnancy, Outcomes, and Social Factors in China: Findings From a Nationwide Population-Based Survey. Sex Med 2019, 7(4):396402.

9. WHO: Global health estimates 2015: deaths by cause, age, sex, by country and by region, 20002015. Geneva: WHO; 2016.

10. Shu C, Fu A, Lu J, Yin M, Chen Y, Qin T, Shang X, Wang X, Zhang M, Xiong C et al: Association between age at first sexual intercourse and knowledge, attitudes and practices regarding 
reproductive health and unplanned pregnancy: a cross-sectional study. Public Health 2016, 135:104113.

11. Animaw W, Bogale B: Abortion in university and college female students of Arba Minch town, Ethiopia, 2011. Sex Reprod Healthc 2014, 5(1):17-22.

12. World Bank: Economic impacts of child marriage: Global synthesis report. Washington, DC: World Bank; 2017.

13. Zenebe $\mathrm{M}$, Haukanes $\mathrm{H}$ : When abortion is not within reach: Ethiopian university students struggling with unintended pregnancies. Int J Equity Health 2019, 18.

14. Yared A, Sahile Z, Mekuria M: Sexual and reproductive health experience, knowledge and problems among university students in Ambo, central Ethiopia. Reprod Health 2017, 14(1):41.

15. Hedayati-Moghaddam MR, Eftekharzadeh-Mashhadi I, Fathimoghadam F, Pourafzali SJ: Sexual and Reproductive Behaviors among Undergraduate University Students in Mashhad, a City in Northeast of Iran. J Reprod Infertil 2015, 16(1):43-48.

16. Honarvar B, Salehi F, Barfi R, Asadi Z, Honarvar H, Odoomi N, Arefi N, Lankarani KB: Attitudes Toward and Experience of Singles with Premarital Sex: A Population-Based Study in Shiraz, Southern Iran. Arch Sex Behav 2016, 45(2):395-402.

17. Sychareun V, Phengsavanh A, Hansana V, Chaleunvong K, Kounnavong S, Sawhney M, Durham J: Predictors of premarital sexual activity among unmarried youth in Vientiane, Lao PDR: the role of parent-youth interactions and peer influence. Glob Public Health 2013, 8(8):958-975.

18. Tang L, Chen R, Huang D, Wu H, Yan H, Li S, Braun KL: Prevalence of condom use and associated factors among Chinese female undergraduate students in Wuhan, China. AIDS Care 2013, 25(4):515523.

19. Essizoglu A, Yasan A, Yildirim EA, Gurgen F, Ozkan M: Double standard for traditional value of virginity and premarital sexuality in Turkey: a university students case. Women Health 2011, 51(2):136-150.

20. Oleribe OO, Okojie OH, Burstow NJ, Taylor-Robinson SD: Premarital sex and condom use among trainee healthcare workers: an exploratory study of selected healthcare training institutions in Enugu State, Nigeria. Pan Afr Med J 2019, 32:7.

21. Somba MJ, Mbonile M, Obure J, Mahande MJ: Sexual behaviour, contraceptive knowledge and use among female undergraduates' students of Muhimbili and Dar es Salaam Universities, Tanzania: a cross-sectional study. BMC Womens Health 2014, 14:94.

22. Akibu M, Gebresellasie F, Zekarias F, Tsegaye W: Premarital sexual practice and its predictors among university students: institution based cross sectional study. Pan Afr Med J 2017, 28:234.

23. Mulu W, Yimer M, Abera B: Sexual behaviours and associated factors among students at Bahir Dar University: a cross sectional study. Reprod Health 2014, 11:84.

24. Mavhandu-Mudzusi AH, Asgedom TT: The prevalence of risky sexual behaviours amongst undergraduate students in Jigjiga University, Ethiopia. He a / $t$ h $s$ a g e $s$ o n $d$ h e i d2016, 21:179186. 
25. Regassa T, Chala D, Adeba E: Premarital Sex in the Last Twelve Months and Its Predictors among Students of Wollega University, Ethiopia. Ethiop J Health Sci 2016, 26(4):351-358.

26. Waktole ZD, Roro AG, Gebretsadik LA: Factors Predicting Responses to HIV/AIDS Prevention Messages among Wollega University Students, Oromia, Ethiopia: A Cross-Sectional Study. Ethiop J Health Sci 2019, 29(4):453-460.

27. Woldeyohannes D, Asmamaw Y, Sisay S, Hailesselassie W, Birmeta K, Tekeste Z: Risky HIV sexual behavior and utilization of voluntary counseling and HIV testing and associated factors among undergraduate students in Addis Ababa, Ethiopia. BMC Public Health 2017, 17(1):121.

28. Regassa N, Kedir S: Attitudes and practices on HIV preventions among students of higher education institutions in Ethiopia: the case of Addis Ababa University. East Afr J Public Health 2011, 8(2):141154.

29. Kebede A, Molla B, Gerensea H: Assessment of risky sexual behavior and practice among Aksum University students, Shire Campus, Shire Town, Tigray, Ethiopia, 2017. BMC Res Notes 2018, 11(1):88.

30. Derbie A, Assefa M, Mekonnen D, Biadglegne F: Risky sexual behaviour and associated factors among students of Debre Tabor University, Northwest Ethiopia: a cross-sectional study. Ethipia J Health Dev 2016, 30:11-18.

31. Teferra TB, Erena AN, Kebede A: Prevalence of premarital sexual practice and associated factors among undergraduate health science students of Madawalabu University, Bale Goba, South East Ethiopia: institution based cross sectional study. Pan Afr Med J 2015, 20:209.

32. Ahmed FA, Moussa KM, Petterson KO, Asamoah BO: Assessing knowledge, attitude, and practice of emergency contraception: a cross- sectional study among Ethiopian undergraduate female students. BMC Public Health 2012, 12:110.

33. Gebresllasie F, Tsadik M, Berhane E: Potential predictors of risk sexual behavior among private college students in Mekelle City, North Ethiopia. Pan Afr Med J 2017, 28:151.

34. Dingeta T, Oljira L, Assefa N: Patterns of sexual risk behavior among undergraduate university students in Ethiopia: a cross-sectional study. Pan Afr Med J 2012, 12:33.

35. Tololu AK, Belda SS, Worku BA, Deressa GN, Hassan RN, Gudeta TM: Premarital sexual practice and associated factors among robe TVET students at robe town, bale zone, Oromia region, southeast Ethiopia, 2016. . MOJ Public Health 2017, 5:193-203.

36. Alamrew Z, Bedimo M, Azage M: Risky Sexual Practices and Associated Factors for HIV/AIDS Infection among Private College Students in Bahir Dar City, Northwest Ethiopia. Public Health 2013, 2013:763051.

37. Yarinbab TE, Tawi NY, Darkiab I, Debele F, Ambo WA: Determinants of Risky Sexual Behaviors among Students of Mizan Aman College of Health Science, Southwest Ethiopia: Cross-Sectional Study. Int J Womens Health Wellness 2018, 4:074.

38. Kassie BA, Yenus H, Berhe R, Kassahun EA: Prevalence of sexually transmitted infections and associated factors among the University of Gondar students, Northwest Ethiopia: a cross-sectional 
study. Reprod Health 2019, 16(1):163.

39. Arega WL, Zewale TA, Bogale KA: Premarital sexual practice and associated factors among high school youths in Debretabor town, South Gondar zone, North West Ethiopia, 2017. BMC Res Notes 2019, 12(1):314.

40. Bogale A, Seme A: Premarital sexual practices and its predictors among in-school youths of Shendi town, west Gojjam zone, North Western Ethiopia. Reprod Health 2014, 11:49.

41. Mekonnen M, Yimer B, Wolde W: Sexual Risk behaviour and Associated Factors among Governmental Higher Institution Students in Debre Markos Town, North West Ethiopia Public H Open Acc 2018, 2:000121.

42. Musiime KE, Mugisha JF: Factors Associated with Sexual Behaviour among Students of Uganda Martyrs University. International Journal of Public Health Research 2015, 3:85-93.

43. Hoque ME, Ntsipe T, Mokgatle-Nthabu M: Sexual Practices among University Students in Botswana. Gender \& Behaviour 2012, 10:4645-4656.

44. Kassahun EA, Gelagay AA, Muche AA, Dessie AA, Kassie BA: Factors associated with early sexual initiation among preparatory and high school youths in Woldia town, northeast Ethiopia: a crosssectional study. BMC Public Health 2019, 19(1):378. 